\title{
Familia y religión en Buenos Aires: el análisis reticular en una investigación cualitativa con foto elicitación
}

Family and religion in Buenos Aires: network analysis in qualitative research with photo elicitation

Agustina Adela Zaros

Centro de Estudios e Investigaciones Laborales -CONICET, Argentina

agostinazaros@gmail.com

\section{RESUMEN:}

El artículo aborda el estudio de la socialización religiosa en familias de diferentes credos en Buenos Aires con metodología cualitativa; se focaliza en dos aspectos relacionados con las imágenes utilizadas durante la investigación: la recolección de datos con la técnica de la foto-elicitación y el análisis reticular de coincidencias de dichas fotografías. El concepto de memoria atraviesa la investigación donde la reconstrucción del pasado en común implica un sentido compartido del presente y puede dar cuenta de la configuración del vínculo entre familia, tradición y religiosidad. Recordar implica una construcción y al mismo tiempo una legitimación del linaje. Las fotografías - en este caso- emergen como expresión de la identidad familiar que representan momentos de las trayectorias biográficas como puntos de referencia, permitiendo acceder a los recuerdos de sus miembros. El uso del análisis reticular de coincidencias aplicado al contenido de las fotografías establece presencias y ausencias entre los personajes con un análisis que complementa a los datos recolectados con las entrevistas. El análisis reticular de coincidencias permitió comprender lo que las imágenes revelan sobre las relaciones de parentesco, las afinidades y desigualdades al interior de la familia y a nivel generacional. Así, el texto se focaliza en el uso de la foto-elicitación y el análisis reticular, que pueden constituir un aporte metodológico al estudio del fenómeno religioso.

Palabras Clave: Religión, Familia, Foto-elicitación, Análisis reticular de coincidencias, Buenos Aires.

\section{Abstract:}

The article approaches the study of religious socialization in families of different faiths in Buenos Aires with a qualitative methodology, focusing on two aspects related to the images used during the research: data collection with the photo elicitation technique and the network analysis of coincidences of the photographs. The concept of memory is present along the whole research, where the reconstruction of the past in common implies a certain shared sense of the present and offers an account of the configuration of the link between family, tradition, and religiosity. Remembering implies a construction and, at the same time, a legitimation of the family lineage. Photographs emerge as an emblem of family identity that represent moments of biographical trajectories as points of reference, allowing access to the memories of their members. The use of the network analysis of coincidences applied to the content of the photographs identifies presences and absences among the actors that complement the data collected with the interviews. The network analysis of coincidences made it possible to understand what the images reveal about kinship relations, affinities, and inequalities within the family and at a generational level. Thus, the text focuses on the use of photoelicitation and network analysis, which may constitute a methodological contribution to the study of religious phenomena.

KEYWORDS: Religion, Family, Photo-elicitation, Network analysis of coincidences, Buenos Aires.

\section{INTRODUCCIÓN}

El siguiente texto es producto de una investigación cuyo objetivo general fue indagar los cambios socioreligiosos de la transmisión de la religión en el interior de familias de distintas tradiciones religiosas judías, musulmanas, católicas y evangélicas-, desde la perspectiva analítica de la memoria religiosa familiar y con entrevistas con foto-elicitación a 10 familias de Buenos Aires. 
El campo religioso en que se desarrolló la investigación ${ }^{1}$ presenta una diversidad cultural y religiosa a través de diferentes fenómenos ${ }^{2}$, atravesados por procesos de globalización y transnacionalización como formas contemporáneas de construcción de grupos religiosos, y de "regreso a las fuentes" en las tradiciones judía y musulmana (Algranti y Setton, 2009).

Entre los judíos existe una estructura que permite la socialización religiosa institucional desde la infancia, con una red de sinagogas, instituciones educativas y grupos políticos de distinta ortodoxia, desde los conservadores a la presencia de Jabad Lubavitch ${ }^{3}$. Las corrientes ortodoxa, conservadora y reformista del judaísmo se distinguen en relación a la interpretación de la Torá y a sus prácticas. Sin embargo, la mayoría de los judíos que viven en Buenos Aires no se encuentra afiliado a ninguna institución aunque participe de ella (Setton, 2009). El campo judío de este trabajo está compuesto por dos comunidades judías conservadoras de Buenos Aires.

Las primeras instituciones musulmanas se originaron con los migrantes a fines del siglo XIX. Actualmente el islam en Argentina es diverso y fragmentado (Montenegro, 2008), con diferentes corrientes de pensamiento dentro del islam y con diferentes procedencias: sunnita (en su mayoría), shiitas, alauitas y drusos. Además, existen en Buenos Aires dos grupos sufís y miembros del movimiento tabligh. La religión islámica supo adaptarse a los ambientes socioculturales de las sociedades huésped, en algunos casos tomando rasgos característicos de la cultura argentina. Tanto la comunidad musulmana como la judía argentina tienen una presencia histórica en el país y participaron de la formación del Estado nacional argentino. El campo islámico está formado por una institución tradicional islámica que frecuentan principalmente descendientes de sirios y libaneses, y una orden sufí formada en su mayoría por conversos.

Argentina como nación católica es producto de un catolicismo ligado a la identidad nacional, que se fue gestando a partir de los años 30 en espacios de socialización marcados por una fuerte presencia católica, con una estructura de parroquias, diócesis, etc. (Mallimaci, 2015) ${ }^{4}$. Las familias católicas entrevistadas pertenecen a los que Giménez Beliveau (2016) denominó “católicos militantes" es decir, laicos con participación, pertenencia a grupos de la Iglesia, que cumplen con los sacramentos y rituales con periodicidad. Es decir, provienen de otros espacios católicos productores de sociabilidades al interior de la institución como movimientos eclesiales, grupos organizados, juveniles, políticos, etc.

Por último, las familias evangélicas entrevistadas son herederas de las tradiciones protestantes que se formaron en el país a principios del siglo XX, manteniendo un modelo de Iglesia privado y familiar. Las iglesias históricas de corte misional llegan al país entre 1881 y 1924, y los inmigrantes integran las primeras iglesias evangélicas (Algranti, 2010). En la actualidad los evangélicos constituyen el grupo religioso con mayor crecimiento en el país, con presencia en la escena pública, liderazgos personalistas y megaiglesias. El campo se realizó en dos iglesias que descienden de la vertiente de los Hermanos Libres.

El texto está organizado de la siguiente manera: una introducción del marco conceptual que sustenta la investigación; un apartado metodológico y el desarrollo del análisis reticular con el programa NetCoin, y finalmente algunas reflexiones sobre las coincidencias que muestran las fotografías en este estudio sobre familia y religión en Buenos Aires.

\section{Memoria, FAMiLia y FOTOGRAFía}

Las fotografías constituyen un emblema de la identidad familiar (Kellerhals, Ferreira y Perrenoud, 2002), representan momentos de las trayectorias biográficas que muchas veces la muerte cristaliza en las relaciones de transmisión. Para el investigador la fotografía puede constituir un documento, pero para el entrevistado es un objeto que será legado a quienes lo sucedan (Carvalho, 2005) ${ }^{5}$, y que constituye un espacio que revela tanto las relaciones de parentesco como las afinidades y las desigualdades. Las fotografías familiares tienen 
potencial documentalista, en cuanto materialización de contenidos sociales -valores y representaciones- y por permitir variadas lecturas y temporalidades respecto a lo concebido, percibido y vivido (Franco, 2015).

Moreira Leites (2000) afirma que "el sentido que encierra la fotografía es comprender la continuidad de un proceso que hermana al destino de esos fantasmas congelados" ${ }^{6}$. En su investigación sobre migrantes europeos en San Pablo a principios del siglo XX da cuenta de cómo emergen condiciones en las cuales la fotografía ocupa un papel simbólico en la legitimación de la familia.

La familia es también un grupo en el cual existen roles fijados por reglas y costumbres precedentes a cada integrante. Como afirma Halbwachs (1925):

...en el cuadro de la memoria familiar, hay figuras y hechos que tienen la función de ser puntos de referencia: pero cada una de estas figuras expresa un carácter en su totalidad, cada uno de estos hechos resume un entero período de la vida del grupo, son al mismo tiempo imágenes y nociones (p. 38).

Es en el trasfondo doméstico y familiar donde el fluir del tiempo histórico se entrecruza con la construcción intersubjetiva de la realidad y con la corporalidad implícita en la manipulación cotidiana del ambiente (Rampazi, 2010).

En relación con esto, Jedlowski (2008) añade:

En el reconocerse quien es, no puedo dejar de reconocer el rol que la tradición en la que crecí por heterogénea que pueda ser, jugó en dar forma a mis predisposiciones. No se trata solo del hecho que mi experiencia está en gran parte constituida por percepciones, significados y rutinas que yo mismo incorporé al interior de una cultura compartida con otros, lo que es tradición: conectan a cada uno a un tiempo y a lugares, rituales, palabras, conductas, que pertenecen a una cultura (p. 189).

Si seguimos a Muxel (2002), la memoria familiar es el presente de un pasado, custodio de los recuerdos de la infancia y fiel servidor de los deseos, de los interesados pero también de las reivindicaciones y de las instancias del hoy. Por su parte, Halbwachs (1925) afirma que la familia tiene una memoria propia -al igual otros tipos de comunidad-en la cual se insertan las relaciones de parentela y los eventos familiares.

Tener un pasado en común implica un cierto sentido compartido del presente (...) saber que descendemos de algún antepasado común nos hace sentir en cierto modo "conectados". Tal solidaridad es el sentimiento de base que subyace a las comunidades de sangre entendida como lenguajes, sistemas de parentela cognaticia, grupos de descendencia (Zerubavel, 2005, p. 110).

El autor estudió cómo el pasado es registrado y organizado en las mentes, y afirma que el ser social presupone la capacidad de probar cosas que les sucedieron a los grupos de pertenencia anteriores a nuestra llegada como si fueran parte de nuestro pasado individual. Para este autor, recordar es también una actividad guiada por normas del recuerdo -inequívocamente social- que nos dicen qué debemos recordar y qué olvidar.

Para Aleida Assmann la formación cultural es el medio a través del cual la identidad colectiva está construida, es mantenida a través de las generaciones, y se reproduce. En su interior la religión conserva su estructura anacrónica y aquello que no puede ser olvidado.

Sobre lo que debe ser recordado, distingue entre memoria funcional y memoria de archivo, la primera constituiría un depósito de contenidos que pueden ser utilizados y la segunda es el cúmulo de recuerdos sin organización que representa el trasfondo de la primera.

Los recuerdos se insertan en el campo de fuerza de un preciso significado, se diferencian de los datos sensibles y de las experiencias precedentes. La memoria produce sentido, y el sentido estabiliza la memoria. Es siempre objeto de construcción y de un significado que se estabiliza posteriormente (Assmann, 2002, p. 151).

Para esta autora, a nivel cultural el sujeto es portador de la propia memoria funcional, mientras que la memoria funcional de una nación está compuesta de sujetos colectivos que comparten una precisa reconstrucción del pasado. Emerge así la importancia de la afirmación del grupo que organiza la memoria funcional a partir de los recuerdos de la memoria archivo. 
Marie-Claire Lavabre, por su parte, agrega que la memoria no se refiere solo a la capacidad de un individuo de fijar, conservar y recordar el pasado. Ella evoca, desordenadamente, todas las formas de presencia de un pasado: "todo es memoria del momento en el cual la relación con el pasado implica la identidad de los grupos sociales" (Lavabre, 2009) ${ }^{7}$.

"En el ámbito de las religiones abrahámicas, la memoria goza de una posición privilegiada. En el génesis, la alianza entre Dios y su pueblo se renueva a través del recuerdo (Gen. 9, pp. 14-15)" (Montesperelli, 2003, p. 30). En relación con esto, la configuración del vínculo entre tradición y religiosidad se encuentra presente en la resignificación de la idea de familia con reinterpretaciones generacionales que pueden llevar a la producción de nuevas prácticas y significados.

En una sociedad como la postmoderna, en la cual el individualismo dominante empuja más hacia la dimensión subjetiva que hacia la comunitaria, produce consecuencias también en el ámbito religioso, donde la memoria religiosa constituye un momento de revisión de la existencia personal a la luz de principios de vida explícitamente reconocidos (Abbruzzese, 2010, p. 78).

En relación con esto, Jedlowski afirma que la originalidad de Halbwachs consiste en incluir el postulado de que el pasado que se presenta en el acto de recordar no es un pasado que vuelve sino una reconstrucción efectiva del pasado mismo, una reformulación que está sujeta cada vez a ajustes y revisiones, que derivan de las modificaciones de los puntos de vista que operan en el presente. Según esta perspectiva, la memoria emerge como un conjunto dinámico, lugar de selecciones, de reinterpretaciones y reformulaciones del pasado. Su función consiste, más que en proveer imágenes fieles del pasado, en preservar los elementos del pasado que garantizan a los sujetos el sentido de su propia continuidad y la afirmación de su propia identidad (Jedlowski, 1989).

El autor recupera tres líneas de la obra de Maurice Halbwachs:

la memoria individual que siempre es memoria colectiva (en el sentido de un necesario encuadramiento en estructuras sociales de pensamiento, o de madurez en relación a la pertenencia del individuo a determinados ambientes sociales 2) la memoria (individual o colectiva) representa la continuidad del pasado en el presente sólo a condición de someter las imágenes del pasado a un trabajo constante de selección, síntesis y reconstrucción movilizados por los intereses del presente. 3) la memoria es un elemento de la identidad -tanto a nivel individual como colectivo- pero es también la expresión: la identidad presente, en otras palabras, se expresa en determinadas interpretaciones del pasado, tendencialmente congruentes, de las que obtiene fuerza (Jedlowski, 1989, p. 52).

Así, la importancia del concepto de memoria colectiva está en relación con la experiencia de compartir un recuerdo con el grupo y con las reinterpretaciones que cada reconstrucción del pasado comporta. Por último, este trabajo dialoga tanto con las tradiciones estructuralista y funcionalista (Durkheim y Halbwachs) como con la constructivista de Mead, que insisten sobre la preeminencia de la definición del pasado como vínculo que limita la construcción completamente arbitraria del presente (Cossu, 2008) ${ }^{8}$.

Hasta aquí hemos presentado la perspectiva teórica que fundamenta la metodología elegida, la cual será objeto del próximo apartado.

\section{Metodología}

A nivel metodológico, se realizó observación participante (Ameigeiras, 2006) en dos templos judíos conservadores, dos iglesias evangélicas que se autodenominan independientes y que en su origen fueron de la denominación Hermanos Libres; una iglesia católica, una institución islámica y una tariqa sufí de la orden Yerrahi. Se realizaron durante seis meses, en 2016, observaciones en los rituales, reuniones y servicios religiosos, así como en actividades semanales (cursos de Torah, escuela bíblica, grupos juveniles, etc.) en donde se conoció a miembros de las familias entrevistadas ${ }^{9}$. El contacto con las familias se realizó durante las sesiones de observación participante. 
Se seleccionó una muestra según propósitos (Maxwell 2004), dirigida y de sujetos tipo, con el objetivo de profundizar el análisis de un determinado grupo social. Se realizaron entrevistas que dieran cuenta de la pluralidad de familias existente en el campo -tomadas como construcciones operativas (Patton, 2015) - y las características específicas de cada comunidad religiosa.

Las familias finalmente entrevistadas residen en el Área Metropolitana de Buenos Aires; algunos de sus miembros son participantes activos de las comunidades donde se realizó la etnografía, tienen dos y tres generaciones en los vínculos de parentesco a los que accedió la investigadora y se reconocen pertenecientes a una tradición religiosa. En algunos casos se conoció al matrimonio o a uno de los miembros de la familia, como la madre o los hijos, en los servicios religiosos o en las actividades vinculadas con la institución religiosa que la investigadora frecuentaba semanalmente. El momento de las entrevistas -realizadas al matrimonio por un lado y a los hijos y nietos individualmente- se produjo seis meses después del inicio de las observaciones, por lo cual la investigadora no era una desconocida, tenía familiaridad con el funcionamiento de la comunidad de pertenencia y con los entrevistados.

Se trata de 10 familias -en dos y tres generaciones-, de las cuales dos son evangélicas $\left(\mathrm{n}^{\circ} 1\right.$ y $\left.\mathrm{n}^{\circ} 8\right)$ y dos católicas $\left(\mathrm{n}^{\circ} 4 \mathrm{y} \mathrm{n}^{\circ} 10\right)$, tres son musulmanas $\left(\mathrm{n}^{\circ} 2, \mathrm{n}^{\circ} 5\right.$ y $\left.\mathrm{n}^{\circ} 7\right)$ y tres judías ( $\mathrm{n}^{\circ} 3, \mathrm{n}^{\circ} 6$ y $\left.\mathrm{n}^{\circ} 9\right)$.

Fueron entrevistados un total de 17 personas (padre, madre, hijos/as y nietos/as) que integran 10 familias y 4 testimonios privilegiados; tienen entre 17 y 88 años y viven en el Área Metropolitana de Buenos Aires. En relación a las ocupaciones, son profesionales (7), empleados (3), estudiantes (2), jubilados (3), y amas de casa (2). La pareja principal de cada familia (madre y padre) adhiere a la misma confesión y continúan casados, sólo una de las entrevistadas es separada.

En particular sobre la foto-elicitación, se usaron fotografías de sus propios álbumes familiares para estimular y guiar las entrevistas. Éstas fotografías son datos que constituyen una evidencia documental que llamamos complementaria, porque es a través del relato que se vuelven significativas, gracias al trabajo interpretativo del investigador (Rose, 2007).

En relación a los diferentes tipos de información que surge con la foto-elicitación, Harper (2002) afirma que tiene una base física: las partes del cerebro que procesan la información visual son evolutivamente más antiguas que las partes que procesan la información verbal. Así, las imágenes evocan elementos más profundos de la conciencia humana, que se hacen palabras; los intercambios basados únicamente en palabras utilizan menos capacidad del cerebro que los intercambios en los que el cerebro procesa imágenes y palabras.

Los álbumes familiares constituyen una forma de representación material del significado de pertenecer a una familia, y la información se transfiere de generación en generación y representa una materialización de la memoria habitada (Zaros, 2016, 2018). Los principales resultados de la estrategia metodológica destacan que es un llamamiento a las emociones; el uso de la foto sirve de estímulo porque produce una interacción diferente en la entrevista. Los entrevistados recuerdan las historias que las fotos cuentan y, por lo tanto, el foco de la comunicación pasa de la entrevista a la fotografía.

Esta dimensión de compartir experiencias pasadas durante el momento de la entrevista en la propia casa del entrevistado genera una relación con el investigador caracterizada por cierta intimidad y privacidad de ese primer encuentro.

Convivir con una familia, ver cómo discuten acerca de sus retratos, observar su proceso de apropiación y reconocimiento en las imágenes crea nuevos indicadores para la reflexión y la interpretación del retrato de familia (Dines, 2004, p.152).

Se pidió a los entrevistados que tuvieran consigo sus álbumes de familia y se seleccionaron las fotografías que ellos elegían "contar" durante las entrevistas, o que previamente seleccionaban para la entrevista.

Las entrevistas se realizaron en los hogares de los matrimonios, solamente una se realizó en un bar a petición de la pareja; todos llevaron un conjunto de fotos que habían seleccionado para la ocasión. Otros informantes las seleccionaban o las buscaban en el momento de la entrevista, así el orden en que aparecían en el relato era aleatorio y espontáneo mientras decidían cuál mostrar y narrar y cuál no. Todas las imágenes presentadas son 
anteriores a la investigación en donde cada una enmarca también un momento de sus vidas, la foto actúa como marco espacio-temporal y como un archivo familiar de los entrevistados. La fotografía de un pariente ayudaba a reconstruir el boceto del personaje de quien se hablaba. A su vez se reconocían lugares que la fotografía mostraba y que parecían olvidados; se identificaban imágenes de un pasado muy diferente al presente de la entrevista. Se escuchó a madres y padres relatando la infancia de hijos que fallecieron. Lo interesante del relato es la manera de que tuvieron los protagonistas de contarse a sí mismos -y sus vínculos familiares- frente a un otro, la reconstrucción de la historia que encierra la foto, la temporalidad y las emociones.

Las fotografías fueron utilizadas de tres maneras: en la recolección de datos con la técnica de la fotoelicitación, en el análisis de los datos a partir del significado agregado del relato de la fotografía por el entrevistado, y, a partir de la información de la imagen, en el análisis de las presencias/ausencias de los miembros de la familia.

Las imágenes - un total de 100 fotografías pertenecientes al archivo privado de 10 familias argentinasfueron obtenidas durante la recolección de datos. La cantidad mínima de fotos presentadas y cedidas por cada familia es de $2^{10}$ y el máximo de 19; el promedio es de 9,9.

Son en su mayoría fotos sueltas que habían sido seleccionadas para la entrevista, cajas de recuerdos, fotos expuestas en la casa en portarretratos; no tienen en su materialidad la forma de álbumes.

Los documentos visuales abarcan el período desde 1928 hasta 2016 en Buenos Aires, y hay una fotografía, cuya fecha es 1896 tomada en el norte de Italia, en la que aparecen antepasados. El ciclo de tiempo que muestran las fotografías varía en cada familia desde 12 hasta 94 años según la reconstrucción de fechas a partir de las entrevistas realizadas.

Las fotos dan cuenta de los ritos de pasajes como matrimonios, comuniones y festividades religiosas, del nacimiento de los hijos y de los nietos, de los antepasados (abuelos y abuelas, bisabuelos y bisabuelas), de viajes y vacaciones, de reuniones familiares y cumpleaños. Aparece la pareja que se casa, sus hijos y sus nietos en las casas, en destinos turísticos o en escenarios exteriores, en ambientes religiosos y, en menor medida, fotos de estudio. Son principalmente fotos de personas y situaciones más que de objetos y lugares. La selección de fotos destaca momentos significativos en el ciclo de vida de un grupo de personas, que dan cuenta de temporalidades y de las uniones dentro de la red de parentesco. Muestran una familia que cambia, que incorpora nuevos miembros, son momentos en que los miembros del grupo están juntos, comparten una cena en los ámbitos domésticos, y en festividades o viajes, que son ocasiones por fuera de lo cotidiano. En relación a lo religioso, las imágenes dan cuenta de la pertenencia a una comunidad con la que se comparten sus prácticas.

Estas imágenes son las que se analizaron a partir de las apariciones de sus personajes y del contenido de las fotografías utilizando la técnica del análisis de redes, como se ampliará en el próximo apartado.

\section{ANÁLISIS RETICULAR DE COINCIDENCIAS}

NetCoin es un paquete de R gratuito, que funciona en el entorno de este lenguaje de programación y que genera tanto estadísticas como gráficos a partir de un conjunto de variables dicotómicas dispuestas en un conjunto de datos. Realiza un análisis reticular de coincidencias (ARC), cuyo principal objetivo es descubrir una serie de fenómenos, opiniones o características, que en un determinado campo suelen aparecer conjuntamente (Escobar, 2018). Emplea el análisis de redes sociales y se centra en la estructura de los vínculos entre personas u organizaciones mediante el descubrimiento de sus pautas de concurrencia, a fin de proporcionar al investigador sugerencias sobre cómo esta estructurada la realidad (Escobar, 2015).

Como antecedentes del estudio de redes sociorreligiosas con análisis reticular en Argentina, puede citarse a Gustavo Motta (2016), quien analiza las redes de los obispos del Episcopado argentino entre 1999-2005 para pensar la construcción de poder en las elites religiosas. Por su parte, el trabajo de Mosqueira (2014) se detiene en las redes del mundo juvenil cristiano trazando relaciones entre los actores y tipos de vínculos. 
El punto de partida es una matriz con datos de cada imagen: la familia a la que pertenece, los personajes que aparecen, el acontecimiento de la foto, contexto espacio-temporal y la religión de la familia. Esto da lugar a un gráfico en el que se representan como nodos las personas que aparecen en las fotografías; el tamaño es proporcional al número de apariciones, la forma denota el género, y el color la filiación en relación a los entrevistados. Los indicadores más utilizados son los vinculados a la presencia de los diferentes miembros familiares en las fotografías analizadas.

Para denominar a los personajes de modo similar en cada familia se ha empleado la siguiente terminología: padre y madre son respectivamente el hombre y mujer de la pareja entrevistada; los abuelos de la familia se dividen en paternos y maternos, y son en realidad los respectivos padres de la pareja principal. El resto de categorías son literales en relación a la madre y el padre, de este modo: hermano y hermana lo son de la pareja principal, así como hijo e hija, nieto y nieta. De esta manera, se asume que los hermanos/as son de la madre, y cuando dice cuñado/a se entiende que son los hermanos del padre. Los valores de una variable están organizados en denominaciones mutuamente excluyentes dentro de la red de parentesco.

El sujeto que muestra las fotos es el matrimonio, o sea, padre y madre juntos en las familias 3, 4, 6, 8 y 9. En el resto de familias (1, 2, 5, 7 y 10) la relatora es la madre (del matrimonio, sin el cónyugue). Además, en la entrevista a la familia 1 estaban presentes la madre, la hija y la nieta juntas, quienes se alternan en el relato, y, en relación a la familia 2, las relatoras son la madre y la nieta.

Se muestra la presencia o ausencia de cada personaje en la selección de fotografía de cada familia y de su conjunto; a mayor frecuencia de apariciones mayor es el tamaño del nodo que lo representa.

El tipo de relación entre los personajes está determinada según la generación: parental (madres y padres), filial (hijos, hijas y sus parejas), gran parental (abuelos y abuelas), gran filial (nietos y nietas), fraternal (hermanos y hermanas). Llamamos otros familiares al parentesco más extenso, y, por tanto, allí se incluyen sobrinos, tíos, primos, cuñados y antepasados (a partir de los bisabuelos y bisabuelas de los entrevistados/ as). Por último, la categoría conocidos se aplica a los personajes que no son familiares, entre los que hay 3 apariciones de amigos y 2 de bailarines.

IMAGEN 1

Gráfico de diez familias

\section{Las 10 familias}

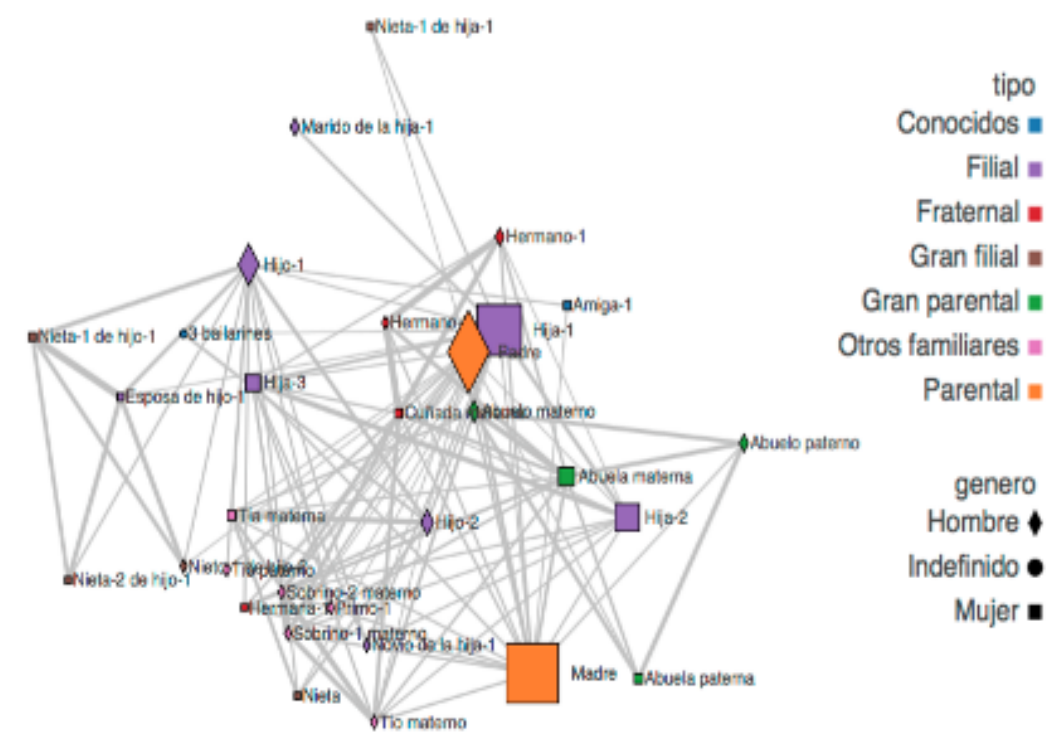

Fuente: Elaboración propia a partir de un total de 100 fotografías.

La madre aparece en 51 de las 100 fotos, el padre, en 37; entre los hijos primogénitos la hija 43 y el hombre, en 16; la segunda hija, en 21, y la tercera, en 11. La abuela materna tiene12 apariciones y el abuelo materno 
6, mientras que los paternos están presentes 4 veces cada uno. Existe menos diferencia entre la pareja de los abuelos paternos que entre los maternos y llama la atención la cantidad de presencias de la abuela materna, tantas casi como de los hijos menores de los matrimonios.

Los enlaces indican la frecuencia de apariciones de los nodos en determinados escenarios, madre y padre son quienes tienen una frecuencia de 27 , es decir que aparecen juntos en las mismas fotografías, seguidos por las fotografías de la primera hija con la segunda (frecuencia de 16) y de la segunda hija con la tercera (9).

El ancho de las líneas que unen a los nodos distingue entre las apariciones más y menos importantes, hecho que responde a una variable cuantitativa. Así, madre y padre son las personas con mayores vínculos con otros nodos, lo que los hace tener mayor influencia y centralidad en la red familiar.

Por último, sobre el total de las familias y las fotos, la abuela materna tiene 12 enlaces, menos que la madre (16) pero uno más que el padre (11).

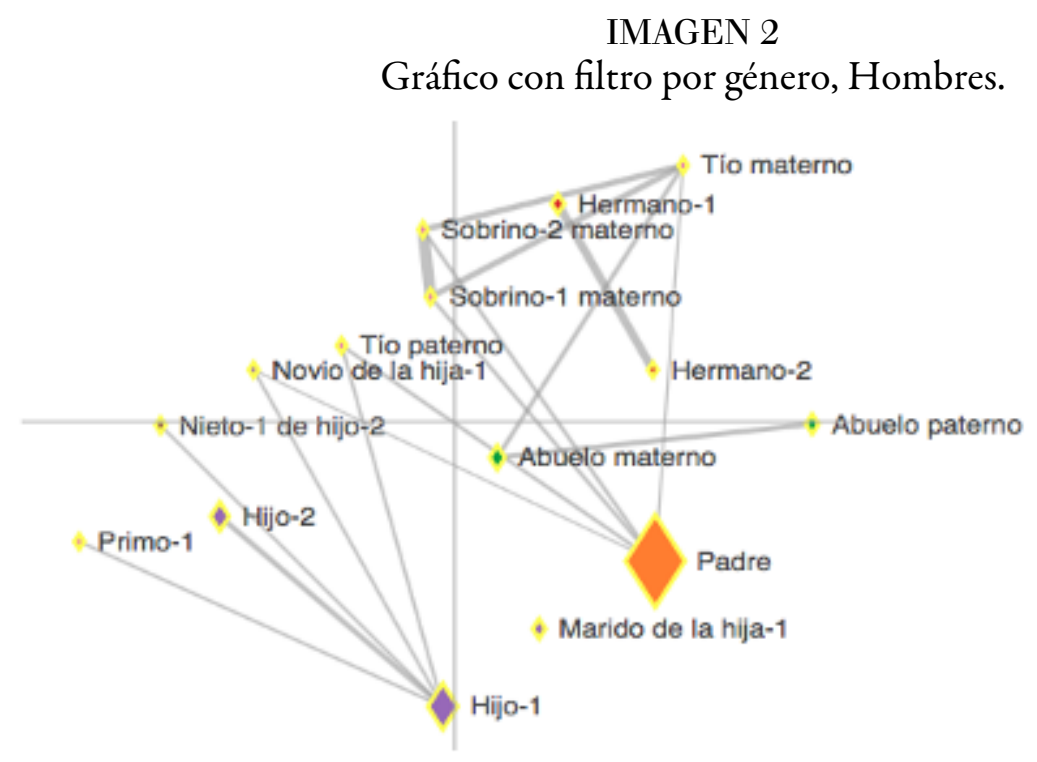

Fuente: Elaboración propia a partir del trabajo de campo.

En relación al género, entre los hombres quien tiene mayor frecuencia de apariciones es el padre con 37 , el primogénito 16; el segundo hijo 8, el abuelo materno 6 y el abuelo paterno 4; por último, un hermano y el marido de la primera hija tienen 4 apariciones. En relación al resto de las figuras -como hermanos, nietos, primos, sobrinos, novio de la primogénita y otros hijos-, sus presencias son menores a 4.

Entre las mujeres, la madre tiene 51 apariciones, la primogénita, 43; la segunda hija, 21; la tercer hija, 11; la abuela materna, 12; la abuela paterna y una tía materna, 4. Los demás personajes -nieta, cuñada, nuera y amiga- tienen menos frecuencia de apariciones.

Las mujeres de la generación parental y filial tienen más apariciones que los hombres. Los abuelos maternos y paternos presentan menos diferencia del número de presencias entre sí que las abuelas maternas y paternas. Por último, se destaca que la abuela materna tiene una frecuencia mayor que la hija menor. 


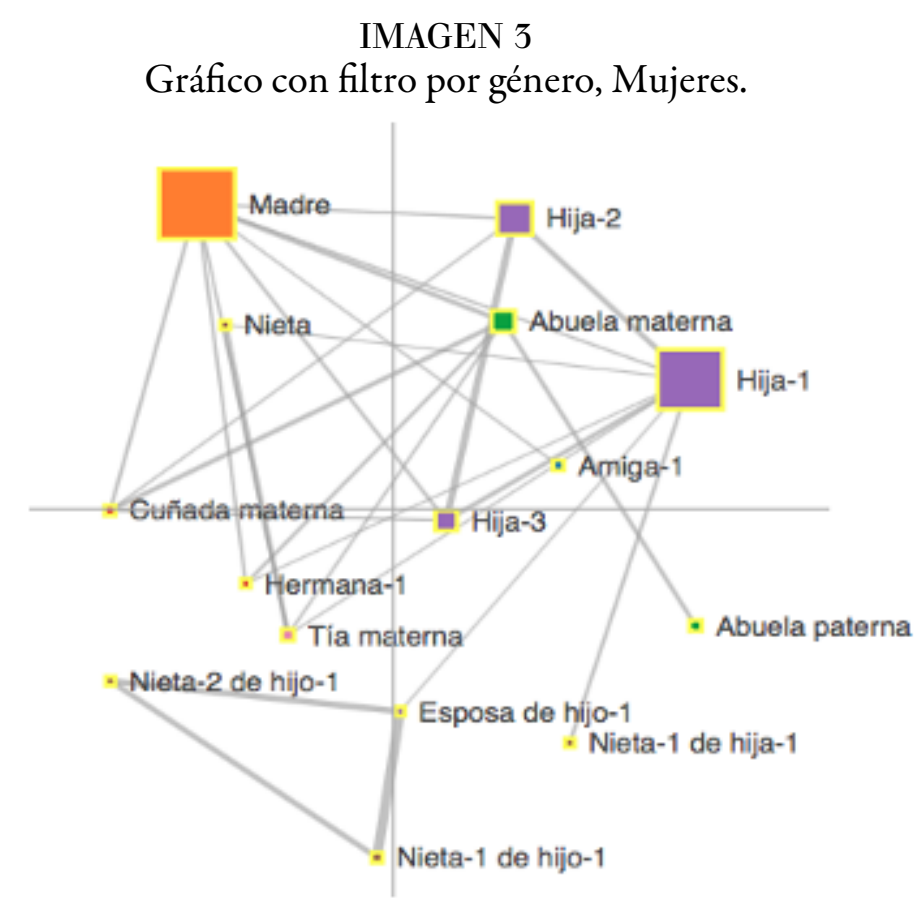

Fuente: Elaboración propia a partir del trabajo de campo.

Entre las dos familias evangélicas figuran con mayor frecuencia de apariciones los personajes del núcleo familiar directo, formado por madre, padre, hijas, y los abuelos maternos. Tanto la primogénita, como la segunda hija y la madre tienen el mismo número de apariciones (9), mientras que el padre (8) y la tercera hija (6) son menos frecuentes. En las fotografías de las familias católicas, la hija primogénita es quien tiene más apariciones (9); supera a la figura de la madre (7), a la del padre (5) y a la de los hermanos (segunda hija, 5; primogénito, 2; segundo hijo, 2).

Entre las fotografías de las tres familias musulmanas, dos corresponden a mujeres convertidas a partir de las cuales hay una ruptura con los orígenes católicos de sus padres. En las fotos de las dos mujeres que fueron entrevistadas (ninguna de ellas está casada con su pareja), los personajes que aparecen son el núcleo directo de linaje materno, es decir, madres, hijos/as, un hermano, cuñada y nietos. En la tercera familia, compuesta por descendientes de sirios que continúan una tradición en la que predominan más las prácticas culturales árabes que las religiosas islámicas, las figuras del abuelo, abuela, bisabuelo y bisabuela maternos están presentes. En el gráfico que muestra el resultado de las fotografías de las tres familias que se reconocen musulmanas, el personaje con mayores apariciones es la hija primogénita (13), seguida por la madre (10), el hijo mayor (7) y la abuela materna (3).

En cambio, la figura que más apariciones tiene en las fotografías de las familias judías es la madre (25), un 64,10\%. Le siguen el padre con 21 apariciones y 53,85\%, los hijos/as (primogénita, 12; segunda hija, 7; primogénito, 7; tercera hija, 5), y la abuela materna, con 5 apariciones, representa el 12,2\% del total de las fotografías de las familias judías.

En estas familias se verifica la presencia de una familia extensa en la que intervienen sobrinos, hijos, nietos, los cuatro abuelos, un primo y una madrina. Lo mismo ocurre entre las familias judías -con presencia de primos, sobrinos, cuñados, tíos y antepasados-, con particular mención a las hijas mujeres y a la abuela materna (con 5 apariciones, abuelo materno, 2; abuela paterna, 2; abuelo paterno, 3).

La figura de la abuela materna aparece 3 veces en una familia católica, lo que representa el 17,65\%, y el $10,71 \%$ en una musulmana, pero donde tiene más apariciones es en las familias judías (5), un 12,82 \% en relación al total de las fotografías de las familias de esa religión. 
Sobre los vínculos entre actores -graficados en las líneas que unen los nodos- también es interesante mencionar que la abuela materna tiene 4 enlaces en las familias evangélicas, 6 en las musulmanas y católicas, y 9 en las familias judías.

IMAGEN 4

Gráfico con filtro, familias judías.

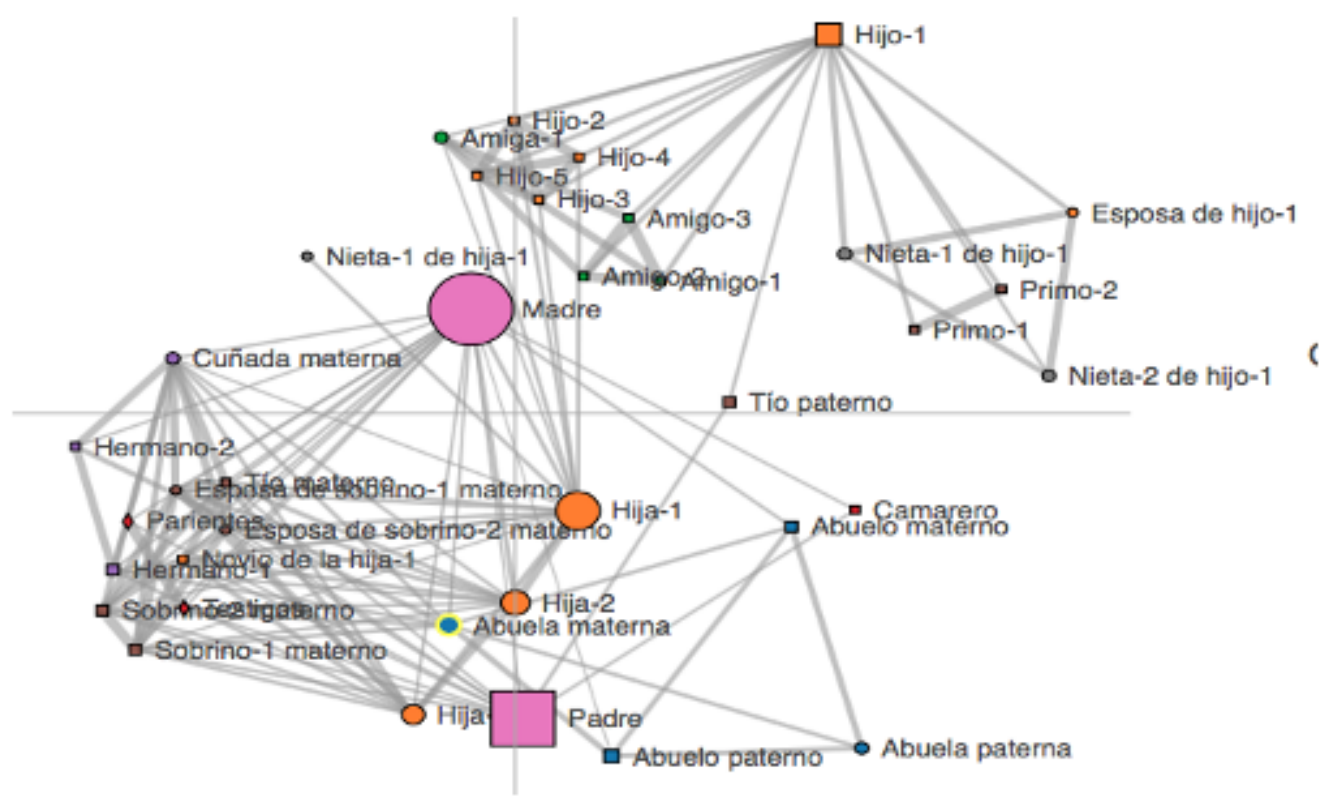

Fuente: Elaboración propia a partir de los datos de tres familias judías.

De manera general, por las presencias que emergen del análisis reticular, las abuelas maternas son elegidas en la selección de las fotografías de los entrevistados más los nietos, cuyas apariciones son menores, una o dos veces como máximo. Esto quiere decir que los entrevistados resaltan la figura de sus abuelas desde el lugar de nietos y nietas, pero no a sus nietos ahora que están en el lugar de abuelos y abuelas. Asimismo, los entrevistados que ocupan el lugar de padres y madres eligen fotos de sus hijos e hijas más que de sus propios padres y nietos/as.

\section{Conclusiones}

El programa netCoin me permitió comparar distintas familias a partir de los datos proporcionados por las fotografías donde dichas apariciones y ausencias muestran lo visible, y al mismo tiempo permiten un análisis adicional de la imagen como documento que puede ser leído como un texto sobre la red de parentesco. Se ha utilizado este análisis de las apariciones de los diferentes miembros familiares en las fotografías analizadas, cuya lógica es similar al análisis de contenidos. De esta manera, es una representación gráfica de los datos -y fundamentalmente de los miembros de las familias- que complementa el análisis de la narrativa de los entrevistados. Los personajes visualizados en red permiten ver las relaciones, los vínculos, hacer un corte por género, por religión, o por los enlaces entre nodos. Principalmente fue valioso porque los resultados del análisis tienen una correspondencia con el análisis cualitativo - paralelo- de las entrevistas, el cual otorga protagonismo a las abuelas maternas, vinculadas especialmente a los recuerdos religiosos de los entrevistados.

Quienes son abuelos al momento de la entrevista recuerdan a sus propios abuelos, en cambio quienes son padres -y en algunos casos también abuelos- presentan más fotografías de sus hijos. Es una reconstrucción 
del pasado en función de roles ocupados en el pasado dentro de la red de parentesco en el primer caso, y de las actuales, en el segundo; en ambas esa reconstrucción está relacionada con la descendencia familiar.

Sobre el período de la vida de las familias en que tienen mayor relevancia las fotografías, destacan los primeros años del matrimonio, con el nacimiento de los primogénitos - con mayor frecuencia de apariciones en las familias católicas-.

Se destaca el valor del matrimonio en la cultura argentina, su función reproductiva y de ampliación de la parentela. Dan cuenta de esto las fotografías de las bodas religiosas y civiles, que aparecen en todas las familias que transitaron ese rito de pasaje. A nivel generacional, el total de apariciones de la abuela materna supera las apariciones de hija menor y pertenecen al mismo período.

En relación con el género, se evidencia la predominancia femenina entre las familias judías más que en otras tradiciones estudiadas. En esta tradición, las mujeres son las figuras de la familia en quienes recae la función de transmisión de la religión biológicamente y en el espacio doméstico.

Por último, las fotografías presentadas en las entrevistas reafirman la descendencia de los linajes, tanto de la comunidad de sangre como de la comunidad de fe de las familias entrevistadas que mantuvieron la tradición religiosa transmitida por sus antepasados.

De esta manera, el estudio de las apariciones y ausencias de los personajes en las fotografías representa visualmente ciertas funciones sociales en el interior del parentesco y la relevancia del rol de los parientes en relación a la memoria religiosa familiar.

\section{Bibliografía}

Algranti,J.(2010). Política y religión en los márgenes. Nuevas formas de participación social de las mega-iglesias evangélicas en la Argentina. Buenos Aires: Ediciones Ciccus.

Algranti, J., y Settón, D. (2009). Habitar las instituciones religiosas: corporeidad y espacio en el campo judaico y pentecostal en Buenos Aires. Alteridades, 38, 77-94.

Assman, A. (2002). Ricordare. Forme e mutamenti della memoria culturale. Bologna:Il Mulino.

Carvalho, C. (2005). Coisas de Familia: Ana\#lise Antropolo\#gica de Processos de Transmissa\#o Familiar (Tesis doctoral inédita). Universidade do Estado do Rio de Janeiro, Rio de Janeiro, Brasil.

Cossu, A. (2008). Problemi e tendenze di ricerca nella sociologia della memoria. Etnografia e ricerca qualitativa, 2, 317-329. doi: https://doi.org/10.3240/33311

Dias Duarte, L. F. (2008). Três famílias: identidades e trajetórias transgeracionais nas classes populares. Rio de Janeiro: FGV editora.

Dines Schreiber, Y. (2004). Um Outro Álbum de Família: Retratos de Migrantes. Revista Chilena de Antropología Visual, 4, 138-156.

Escobar, C., y Tejero, C. (2018). El análisis reticular de coincidencias. EMPIRIA. Revista de Metodologi\#a de Ciencias Sociales, 39, 103-128. Doi: https://doi.org/39.2018.20879

Escobar, M., y Gómez Isla, J. (2015). La expresio\#n de la identidad a trave\#s de la imagen: los archivos fotogra\#ficos de Miguel de Unamuno y Joaqui\#n Turina. Revista Espan\#ola de Investigaciones Sociolo\#gicas, 152, 23-46. doi: http://doi.org/105477/cis.reis.152.2

Franco de Alcantara, P. (2015). Entre o visi\#vel e o na\#o visi\#vel. Os potenciais etnograficos dos retratos de família numa comunidade rural de Mina Gerais. Cadernos de Arte e Antropologia, 4(1), 111-126. doi: https://doi.or $\mathrm{g} / 10.4000 /$ cadernosaa. 866

Frigerio, A.(1993). Perspectivas actuales sobre conversio\#n, deconversion y lavado de cerebro en nuevos movimientos religiosos. En A. Frigerio (Ed.), Nuevos Movimientos Religiosos y Ciencias Sociales (pp. 46-80). Buenos Aires: CEAL.

Giménez Béliveau, V. (2016). Católicos militantes. Buenos Aires: Eudeba.

Halbwachs, M. (1925). Memoria di famiglia. Roma: Armando. 
Harper, D. (2002). Talking about pictures: a case for photo elicitation. Visual Studies, 17(1), 13-26. doi: https://do i.org/10.1080/14725860220137345

Jedlowski, P. (2008). Il sapere dell'esperienza. Roma: Carocci.

Jedlowski, P. (1989). Memoria, esperienza e modernità. Milano: Franco Angeli.

Kellerhals, J., Ferreira, C., y Perrenoud, D. (2002). Linguagens do parentesco: lo\#gicas de construça\#o identita\#ria. Ana\#lise Social, 37(163), 545-567.

Lavabre, M. C. (2009). La memoria fragmentada. ¿Se puede influenciar la memoria? Revista de Anthropologia y Sociologia, 11, 15-28.

Lins de Barros, M. (Org) (2006). Familia e geraçoes. FGV Editora: Rio de Janeiro.

Lins de Barros, M. (1989). Memória e Família. Estudos Históricos, 2(3), 29- 42.

Mallimaci, F. (Comp) (2013). Atlas de las creencias religiosas en Argentina. Buenos Aires: Biblos.

Mallimaci, F. (2015). El mito de la Argentina laica. Catolicismo, politica y Estado. Buenos Aires: Capital Intelectual.

Maxwell, J. (2004). Qualitative Research Design an Interactive Approach. Applied Social Research Methods 2nd edition. London: SAGE Publications.

Montenegro, S. (2015). Formas de adhesión al Islam en Argentina: conversión, tradición, elección, reasunción y tránsito intra-islámico. Horizonte, 13(38),674-705. doi: http://dx.doi.org/10.5752/P.2175-5841.2015v13n38 p 674

Montesperelli, P. (2003). Sociologia della memoria. Roma-Bari: Laterza.

Moreira Leites, M. (2000). Retratos de Familia. Sao Paolo: FAPESP.

Mosqueira, M. (2014). Santa Rebeldi\#a. Construcciones de juventud en comunidades pentecostales del A\#rea Metropolitana de Buenos Aires (Tesis doctoral inédita). Universidad de Buenos Aires, Buenos Aires, Argentina.

Motta, G. (2016). Las redes en las e\#lites. Un enfoque alternativo para abordar la construccio\#n de poder intrainstitucional: el caso de la Conferencia Episcopal Argentina (1999-2005). Sociedad y Religión, 26(46), $11-51$.

Muxel, A. (2002). Individu et mémoire familiale. Paris: Nathan.

Patton, M. (2015). Qualitative Reseach \& Evaluation Methods. Integrating Theory and Practice. Thousand Oaks (California): Sage.

Rampazi, M. (2010). Lo spazio-tempo della casa. En G. Mandich (Ed.), Culture quotidiane (pp. 17-33). Roma: Carocci.

Ricoeur, P. (2004). La memoria, la historia, el olvido. Buenos Aires: Fondo de cultura económica.

Rose, G. (2007). Visual methodologies. London: Sage.

Settón, D. (2010). Judios ortodoxos y judios no afiliados en procesos de interacción. El caso de Jabad Lubavitch de la Argentina (Tesis doctoral inédita). Universidad de Buenos Aires, Buenos Aires, Argentina.

Wynarczyk, H. (2009). Ciudadanos de dos mundos. El Movimiento evangélico en la vida pu\#blica argentina 1980-2001. Buenos Aires: UNSAM Edita.

Zaros, A. (2016). Retratos de una comunidad religiosa: sobre la memoria y las fotos familiares de la comunidad armenia en Padua. Revista Cultura y Religión, 10, 88-106.

Zaros, A. (2018). Los herederos de los abuelos: sobre la socializacio\#n religiosa en familias de diferentes credos en Buenos Aires. Debates do NER, 33, 235-262. doi: https://doi.org/10.22456/1982-8136.79923

Zerubavel, E. (2005). Mappe del tempo. Memoria collettiva e costruzione sociale del passato. Bologna: Il Mulino.

\section{Notas}

1 Sobre los datos estadísticos sobre creencias y actitudes religiosas en la Argentina, ver Mallimaci (2013)

2 Relacionados con el tema de investigacio\#n pueden citarse los trabajos sobre el islam latinoamericano, principalmente en Argentina y Brasil (Montenegro, 2008), relacionado con la pertenencia en el judai\#smo y sus instituciones (Setton, 
2009) y sobre el fenómeno evangélico de iglesias pentecostales (Frigerio, 1993; Wynarczyk, 2009) y neopentecostales (Algranti, 2010).

3 Sobre Javad Lubavitch ver la tesis doctoral de Damián Setton (2010)

4 Sobre el catolicismo argentino ver (Mallimaci, 1996).

5 En su tesis doctoral Carvalho sigue a cinco familias de Rio de Janeiro en diferentes generaciones y da cuenta que la transmisio\#n intergeneracional no es un mecanismo naturalizado, que la herencia es un espacio de asimétrico de diferenciación y desigualdad y, que los bienes cristalizan los vínculos establecidos al interior de la familia.

6 La autora analiza albunes de familia de inmigrantes europeos llegados a San Pablo entre 1890 y 1930.

7 La autora explica el carácter polisémico del concepto de memoria a través de tres paradigmas representados por los autores franceses: Paul Ricoeur, Pierre Nora y Maurice Halbwachs, que constituyen tres maneras relativamente diferentes de pensar la cuestión. En particular, hace referencia a los "lugares de memoria" de Nora, al "trabajo de la memoria de Ricoeur y a los cuadros de la memoria para pensar la "memoria colectiva" de Halbwachs.

8 Las tendencias actuales en los estudios de sociología de la memoria que se interesan en las prácticas concretas de inscripción e incorporación de la memoria que el autor describe la perspectiva presentista, es el presente que produce el pasado, con particular interés en las conmemoraciones y la reconciliación y la creación de un pasado compartido subrayando dos cuestiones: el regreso del individuo concreto como sujeto de la memoria colectiva y el acento sobre las características emotivas de la memoria. Asimismo, algunos autores insisten en una perspectiva sociosemiótica en la que la materialidad de la memoria inscribe representaciones del pasado en sujetos y prácticas definidas y se da relevancia a la contingencia de las prácticas de memoria y a su carácter situado (Cossu, 2008).

9 Asimismo, de las actividades semanales surgieron invitaciones a celebraciones de matrimonio, cenas de fin de año y viajes en comunidad que se incluyeron como oportunidades de realizar etnografía a partir del tiempo, los recursos y los accesos al campo. El diseño de investigación preveía un año de campo entre etnografía y entrevistas para una investigación postdoctoral de dos años. Asimismo, daban cuenta de la riqueza de la información de las familias seleccionadas (Patton, 2015).

10 En este caso no habían seleccionado fotografías; se habló de las dos que estaban expuestas en portarretratos en el living de la casa. 